of water-soluble material, barium sulphate and siliceous material, zinc oxide, and calculations.

The specification is not intended to apply to paints for outside exposure, but requires that such paints shall dry to dead flat opaque coats, adhering well to wood, metal, and plaster, and stand washing with soap and water, and show no material change in color on exposure to light.

\title{
THERMAL EXPANSION OF COPPER AND ITS IMPORTANT INDUSTRIAL ALLOYS.
}

\section{By Peter Hidnert.}

[ABSTRACT.]

DATA on the thermal expansion of 128 samples of copper and its important alloys of various compositions, heat treatments, mechanical treatments, etc., are presented. The specimens contained from 56 to Ioo per cent. copper and were prepared in a number of ways-cast, cast and cold rolled, extruded, extruded and cold worked, hot rolled and cold worked. Most of the samples were examined from room temperature to about $300^{\circ} \mathrm{C}$. (Several specimens were cooled to $-50^{\circ} \mathrm{C}$. and then heated to $+300^{\circ} \mathrm{C}$.)

Practically all available information on the thermal expansion of copper and its alloys is briefly reviewed.

A description of the apparatus and of the preparation of the samples, etc., is given.

Definite mathematical relations were found to exist between the coefficients of expansion and the copper content of most of the alloys investigated (Series II, III, V, VI). In general, the coefficient of expansion increases with a decrease in the copper content. The addition of lead or tin has a decided effect on the coefficient; the former element generally decreases, and the latter increases the coefficient.

Cast and Cold-rolled Copper-zinc Alloys (Series II and III). -In the case of alloys containing 62 per cent. copper it was found that the coefficients did not materially differ in cast or cold-rolled specimens, and for alloys, containing 90 per cent. copper, a similar agreement existed. For alloys with a copper content from about 62 to 90 per cent. the cold-rolled alloys have greater coefficients than the castings, and for alloys containing more than 90 per cent. 
copper the reverse is true. The coefficients of the inside sections of the castings are generally slightly less than those of the outside sections. A relation exists between the density and thermal expansion of the cold-rolled copper-zinc alloys (Series II).

Cast and Cold-rolled Copper-tin Alloys (Series V and VI).The coefficients of the cold-rolled tin alloys are less than those of the castings. Cold rolling and drawing, therefore, cause a diminution in the values of the coefficients.

Hot Rolled and Extruded Samples (Series I, IV, and VI).Owing to the large number of varying elements in the hot-rolled and extruded samples, it was impossible to determine the exact effect of each constituent element. In general, however, the coefficients are greater than the extrapolated values obtained from the quadratic equations of the copper-zinc alloys (Series II and III), showing a tendency toward increasing values as impurities are added.

The differences between the various series of samples are discussed in the section "Comparison of Results" and presented graphically in Figs. 39 to 43 .

\section{METHOD FOR DIFFERENTIATING AND ESTIMATING UNBLEACHED SULPHITE AND SULPHATE PULPS IN PAPER. ${ }^{*}$}

\section{By R. E. Lofton and M. F. Merritt.}

[ABSTRACT.]

THIS paper discusses briefly the two possible bases on which to develop methods of differentiating between unbleached sulphite and sulphate pulps, viz.: ( I ) the different chemical natures of the two pulps due to different cooking treatments, and (2) the different amounts of ligneous matter that may be retained by the two pulps.

The methods followed by other investigators who have studied this problem are given, together with a brief critical commentary on each method. The methods reviewed include: Those used by Paul Klemm, one of whose methods consists in staining with malachite green alone and subsequently examining the color reaction under the microscope, and the second of whose methods consists in staining the fibres with malachite green and then with rosaniline

\footnotetext{
${ }^{1}$ Technologic Paper No. 189.
} 